\title{
Impact of Nonadherence to NCCN Adjuvant Radiotherapy Initiation Guidelines in Head and Neck Squamous Cell Carcinoma in an Underserved Urban Population
}

\author{
Anusha Ponduri, BA ${ }^{1, *}$; David Z. Liao, MD ${ }^{1, *}$; Nicolas F. Schlecht, PhD ${ }^{2,3,4, t}$; Gregory Rosenblatt, $\mathrm{PhD}^{2}$; \\ Michael B. Prystowsky, MD, PhD²; Rafi Kabarriti, MD'5 Madhur Garg, MD, MBA ${ }^{5}$; Thomas J. Ow, MD, MS 2,6; \\ Bradley A. Schiff, MD ${ }^{6}$; Richard V. Smith, $\mathrm{MD}^{6}$; and Vikas Mehta, MD, MPH ${ }^{6, \dagger}$
}

\begin{abstract}
Background: Nonadherence to NCCN Guidelines during time from surgery to postoperative radiotherapy (S-PORT) can alter survival outcomes in head and neck squamous cell carcinomna (HNSCC). There is a need to validate this impact in an underserved urban population and to understand risk factors and reasons for delay. We sought to investigate the impact of delayed PORT with outcomes of overall survival (OS) in HNSCC, to analyze predictive factors of delayed PORT, and to identify reasons for delay. Methods: We conducted a retrospective cohort study in an urban, community-based academic center. A total of 184 patients with primary HNSCC were identified through the Montefiore Medical Center cancer registry who had been treated between March 1, 2005, and March 8, 2017, and met the inclusion and exclusion criteria. The primary exposure was S-PORT. OS, recurrence, and risk factors and reasons for treatment delay were the main outcomes and measures. Results: Among 184 patients with HNSCC treated with PORT, the median S-PORT was 48.5 days (interquartile range, 41-67 days). The S-PORT threshold that optimally differentiated worse OS outcomes was $>50$ days ( $46.7 \%$ of our cohort; $n=86$ ). Independent of other relevant factors, patients with HNSCC and S-PORT $>50$ days had worse OS (hazard ratio, 2.30; 95\% Cl, 1.34-3.95) and greater recurrence (odds ratio, 3.51; 95\% Cl, 1.31-9.39). Predictors of delayed S-PORT included being underweight or obese, prolonged postoperative length of stay, and age $>70$ years. The most frequent reasons for PORT delay were complications related to surgery $(22.09 \%)$, unrelated medical comorbidities (18.60\%), and nonadherence/missed appointments (6.98\%). Conclusions: Delayed PORT beyond 50 days after surgery was associated with decreased $O S$ and greater recurrence. Identification of predictive factors and reasons for treatment delay helps to target at-risk patients and facilitates interventions in underserved populations.

J Natl Compr Canc Netw, doi: 10.6004/jnccn.2021.7007 Published online September 22, 2021
\end{abstract}

\footnotetext{
${ }^{1}$ Albert Einstein College of Medicine, Bronx; ${ }^{2}$ Department of Pathology, and ${ }^{3}$ Department of Epidemiology \& Population Health, Montefiore Medical Center/ Albert Einstein College of Medicine, Bronx; ${ }^{4}$ Department of Cancer Prevention \& Control, Roswell Park Comprehensive Cancer Center, Buffalo; ${ }^{5}$ Department of Radiation Oncology, Montefiore Medical Center/Albert Einstein College of Medicine, Bronx; and ${ }^{6}$ Department of Otorhinolaryngology-Head and Neck Surgery, Montefiore Medical Center, Bronx, New York.
}

*These authors contributed equally and are co-first authors.

tThese authors contributed equally as senior authors.

\section{Background}

Delays in delivery of care for head and neck squamous cell carcinoma (HNSCC) can increase risk of disease persistence or progression. ${ }^{1,2}$ Among the various delay intervals in HNSCC treatment, delayed time from surgery to postoperative radiotherapy (S-PORT) has been found to be significantly associated with increased mortality. ${ }^{3-10}$ Nonadherence to the NCCN recommendation of initiating postoperative radiotherapy (PORT) 6 weeks after surgery ${ }^{4}$ has been associated with decreased survival, and S-PORT times beyond 7 weeks may cause survival decrements with progressive time delay. ${ }^{8}$

Despite this evidence, HNSCC treatment in the United States has shown poor compliance with S-PORT recommendations in the NCCN Clinical Practice Guidelines in Oncology (NCCN Guidelines) for Head and Neck Cancers. ${ }^{11}$ A review of the National Cancer Database (NCDB) between 2006 and 2014 showed that $>50 \%$ of patients with HNSCC who underwent curative-intent surgery with PORT did not start PORT within the recommended 6 weeks. Furthermore, the percentage of patients who received delayed PORT has increased over time. Failure to receive guidelinedirected care has been associated with socioeconomic, oncologic, and hospital factors. ${ }^{12}$ This is particularly pertinent to the socioeconomically disadvantaged patient population of Bronx, New York, where the mean per capita annual income is $\$ 19,721$. $^{13}$

Although most studies show an association between delayed S-PORT and reduced survival, most of these are based on national cancer data registries, which are heterogeneous, do not analyze recurrence, and may not hold external validity in a local population. In addition, some of the studies have not shown a survival benefit of timely

See JNCCN.org for supplemental online content. 
S-PORT. ${ }^{14-16}$ Recent advancements in intensity-modulated radiotherapy (RT), reduction of treatment time, and combining PORT with chemotherapy make the outcomes of delayed initiation uncertain. ${ }^{17}$ Reasons for S-PORT delay need to be investigated to identify susceptible patients and intervene in a prospective fashion. In this study, we sought to measure the impact of nonadherence to NCCN Guidelines on survival and disease recurrence in patients with HNSCC at a large urban health center, and investigated risk factors predictive of delay.

\section{Methods}

We identified 184 cases of primary adult HNSCC treated at an urban, community-based academic health center between March 1, 2005, and March 8, 2017. The study protocol was approved by the Institutional Review Board (IRB 2018-9739). Patients with HNSCC (including lip/oral cavity, oropharynx, larynx, hypopharynx, nasopharynx, and nose/sinuses) undergoing curativeintent surgery followed by PORT with or without chemotherapy were identified through the cancer registry. Exclusion criteria were stage IVC/metastatic cancer, noncurative palliative treatment, induction chemotherapy, chemotherapy alone, brachytherapy, or incomplete radiation history (see supplemental eFigure 1, available with this article at JNCCN.org).

S-PORT was defined as the number of days between ablative surgery and initiation of adjuvant treatment. An optimal S-PORT threshold was identified through recursive partitioning by using rpart version 4.1-13 (R Foundation for Statistical Computing), based on association with overall survival (OS). The threshold was validated by iterative Kaplan-Meier analysis for OS and comparisons between strata using log-rank tests at increasing S-PORT thresholds of 5 days. Cutoff was designated at the S-PORT time that showed the smallest $P$ value after comparisons by log-rank test.

Multivariable Cox regression models were used to analyze the association between S-PORT delay and OS with adjustment for competing risk factors. The potential for confounding was examined for nonsignificant covariates using a change point estimate criterion for the association between S-PORT and OS. ${ }^{18}$ The proportional hazards assumptions were tested using log-log plots and Schoenfeld residuals. The association between S-PORT delay and recurrence was analyzed using multivariate logistic regression, because time-to-recurrence information was not available. Multivariable logistic regression analysis was also performed to identify risk factors for delayed S-PORT based on the identified threshold. Variable inflation factors were used to confirm the assumption of no multicollinearity. Time to treatment initiation (TTI) was defined as the time from diagnosis to the date of surgery. Staging was determined based on the 7 th edition of the AJCC Cancer Staging Manual. Adherence was defined as compliance with recommended therapy, including completion of recommended chemotherapy and RT at designated intervals. Completion of treatment was defined as completion without regard for how long treatment took to complete. Patients who did not complete the recommended therapy were censored at last observation or at time of death, if sooner. Covariates included in both multivariable models were selected based on a significance threshold of $P<.05$ in univariate analyses. Adjusted hazard ratios (HRs), odds ratios (ORs), and 95\% confidence intervals were generated from the multivariable regression models using SPSS Statistics, version 25.0 (IBM Corp) and R (rpart, version 4.1-13; R Foundation for Statistical Computing) software. Chart reviews were performed to identify reasons for delay in S-PORT, and the reasons for treatment delay were categorized qualitatively.

\section{Results}

\section{Population Characteristics}

The study sample included 184 patients with HNSCC with a median follow-up of 37.5 months (interquartile range [IQR], 17-83 months). Median S-PORT time was 48.5 days (IQR, 41-67 days), whereas median surgical TTI was 36 days (IQR, 23.0-49.5 days). Recursive partitioning analysis and log-rank testing determined that the optimal S-PORT threshold to differentiate OS was $>50$ days. Almost half $(n=86 ; 46.7 \%)$ of the patients in the cohort had S-PORT $>50$ days and were classified as having delayed PORT.

Patient characteristics of our cohort are summarized in supplemental eTable 1 . The most common primary tumor site was the lip/oral cavity ( $\mathrm{n}=84 ; 45.6 \%)$, and most patients $(\mathrm{n}=114 ; 61.9 \%)$ were diagnosed with stage IV disease. Compared with patients with S-PORT $\leq 50$ days, a greater proportion of those with S-PORT $>50$ days were 60 to 69 years of age (43\% vs $23.5 \%$; $P=.042$ ) and had a body mass index (BMI) $<18.5 \mathrm{~kg} / \mathrm{m}^{2}$ (12.8\% vs $\left.4.1 \% ; P=.056\right)$ or a BMI $>30 \mathrm{~kg} / \mathrm{m}^{2}$ (22.1\% vs $\left.15.3 \% ; P=.056\right)$. Patients with S-PORT $>50$ days were less likely to receive concurrent chemotherapy or cetuximab (38.4\% vs $56.1 \%$; $P=.028$ ), were more likely to have a 30 -day postoperative readmission ( $25.6 \%$ vs $12.2 \% ; P=.028$ ), and were more likely to have a prolonged postoperative length of stay (LoS) of 8 to 30 days $(46.5 \%$ vs $28.6 \%$; $P=.007$ ) or $>30$ days $(7.0 \%$ vs $4.1 \%$; $P=.007)$. Adherence to recommended therapy, including receiving concurrent chemotherapy based on NCCN Guidelines, was comparable in both the S-PORT $\leq 50$ days (79.6\%) and S-PORT $>50$ days $(83.7 \%)$ groups.

\section{Effect of S-PORT on Survival and Recurrence}

Five-year OS was $66.4 \%$ for the entire cohort, $53.7 \%$ for those with S-PORT $>50$ days, and $77.5 \%$ for those with 
S-PORT $\leq 50$ days. The 5 -year OS was $67.0 \%$ for the subset of patients with timely TTI based on the threshold of $\leq 60$ days $(\mathrm{n}=160)$ previously determined by using rpart (version 4.1-13). Among patients with TTI $\leq 60$ days, the 5 -year OS was $51.8 \%$ for those with S-PORT $>50$ days and $78.0 \%$ for those with S-PORT $\leq 50$ days. Among those with TTI $>60$ days, the 5 -year OS was $57.3 \%$ for those with S-PORT $>50$ days and $71.1 \%$ for those with S-PORT $\leq 50$ days.

Kaplan-Meier survival analysis showed a difference in the survival probabilities between patients with delayed S-PORT $>50$ days versus $\leq 50$ days within the full cohort (log-rank $P=.006$ ) (Figure 1A) and among the subgroup of patients with TTI $\leq 60$ days (log-rank $P=.012$ ) (Figure 1B). A strong association between survival and delayed S-PORT persisted after adjusting for prognostic factors in a multivariable Cox proportional hazards model including the full cohort (HR, 2.30; 95\% CI, 1.34-3.95) and in the cohort restricted to patients with TTI $\leq 60$ days (HR, 2.27; 95\% CI, 1.25-4.11) (Table 1). TTI was not included as a covariate in survival analysis, because it was not shown to be a confounder of the association between S-PORT and OS as a categorical, continuous, or log-transformed variable (supplemental eTable 2).

The association between S-PORT time and OS was analyzed within subgroups defined by tumor site, stage, and adjuvant treatment modality (RT alone vs concurrent chemotherapy or cetuximab) (supplemental eTable 3). The association was most significant in patients with stage IV disease (HR, 2.21; 95\% CI, 1.18-4.12) and in those with laryngeal cancer (HR, 4.78; 95\% CI, 0.96-23.95). A less significant association was observed with S-PORT $>50$ days and OS in patients with p16-positive oropharyngeal cancer (HR, 2.44; 95\% CI, 0.21-28.20) than in those with p16-negative or undetermined oropharyngeal cancer (HR, 10.81; 95\% CI, 0.96-121.65). S-PORT > 50 days was associated with significantly poorer OS only among patients who received RT without concurrent chemotherapy or cetuximab (HR, 5.80; 95\% CI, 2.06-16.32). The association between S-PORT $>50$ days and OS in patients who received RT with concurrent chemotherapy or cetuximab was not significant (HR, 1.32; 95\% CI, 0.62-2.79).

Logistic regression analysis was used to investigate risk of recurrence. Time to recurrence was not available for analysis, and we excluded 48 patients who were not assessed for recurrence at Montefiore Medical Center. After adjusting for other predictive factors of TTI $>60$ days, BMI, postoperative LoS, treatment adherence, and AJCC final stage, S-PORT $>50$ days (OR, 3.51; 95\% CI, 1.31-9.39) and TTI $>60$ days (OR, 3.57; 95\% CI, $1.05-12.19)$ were both associated with greater risk of recurrence (supplemental eTables 4 and 5). However, the association between delayed S-PORT and recurrence became nonsignificant after further excluding patients with unknown TTI, BMI, postoperative LoS, treatment adherence, or AJCC final stage.

Factors predictive of delayed S-PORT $>50$ days were explored using multivariable logistic regression (Table 2). BMI $<18.5 \mathrm{~kg} / \mathrm{m}^{2}$ versus 18.5 to $30 \mathrm{~kg} / \mathrm{m}^{2}$ (OR, $3.98 ; 95 \%$ CI, 1.11-14.21) and postoperative LoS of 8 to 30 days versus 0 to 7 days (OR, 2.79; 95\% CI, 1.36-5.74) were associated with increased odds of delayed S-PORT. Three other factors had borderline significant associations with delayed S-PORT: postoperative LoS $>30$
A

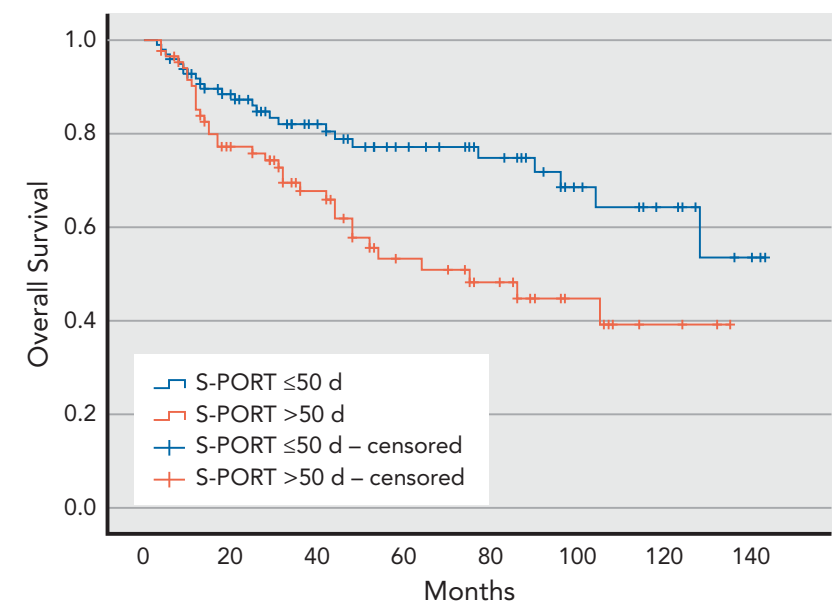

B

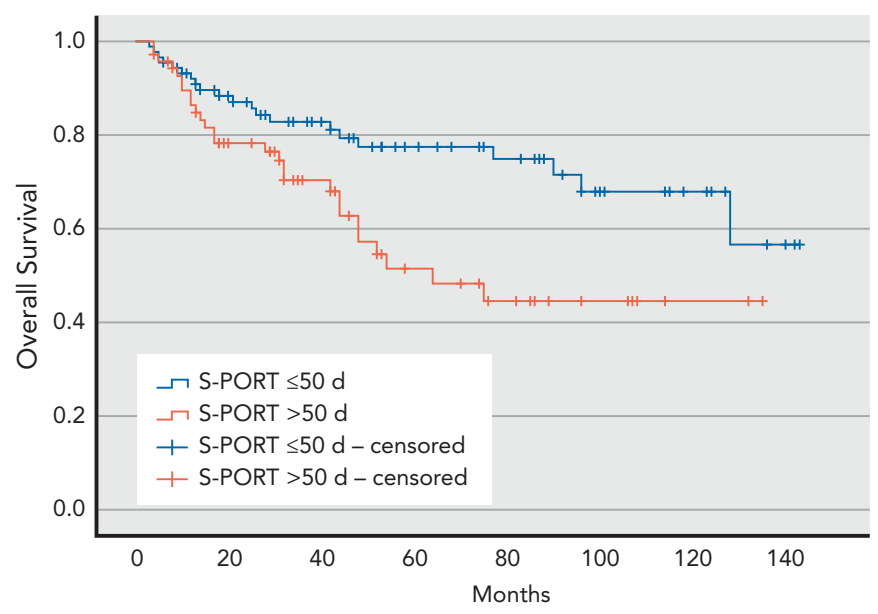

Figure 1. (A) Kaplan-Meier survival estimates based on a S-PORT threshold of 50 days among the entire cohort (N=184). Log-rank (Mantel-Cox) test chi-square, $7.64(P=.006)$. Unadjusted HR for S-PORT $>50$ days, $2.06(95 \% \mathrm{Cl}, 1.22-3.47)$. Adjusted hazard ratio for S-PORT $>50$ days, 2.30 (95\% Cl, 1.34-3.95). (B) Kaplan-Meier survival estimates based on S-PORT threshold of 50 days among patients with TTI $\leq 60$ days $(n=160)$. Log-rank (Mantel-Cox) test chi-square, $6.33(P=.012)$. Unadjusted HR for S-PORT $>50$ days, 2.12 (95\% Cl, 1.22-3.68). Adjusted HR for S-PORT $>50$ days, 2.27 (95\% Cl, 1.25-4.11).

Abbreviations: HR, hazard ratio; S-PORT, time from surgery to postoperative radiotherapy; TTI, time to treatment initiation. 


\begin{tabular}{|c|c|c|}
\hline & $\begin{array}{c}\text { All TTI } \\
(n=184) \\
\text { HR }(95 \% \mathrm{Cl})\end{array}$ & $\begin{array}{c}\text { TTI } \leq 60 \mathrm{~d} \\
(n=160) \\
H R(95 \% \mathrm{Cl})\end{array}$ \\
\hline S-PORT > $>50 d$ & $2.30(1.34-3.95)$ & $2.27(1.25-4.11)$ \\
\hline \multicolumn{3}{|c|}{ Adjuvant therapy adherence } \\
\hline Nonadherent & Ref & Ref \\
\hline Adherent & $0.40(0.22-0.72)$ & $0.28(0.15-0.52)$ \\
\hline Unknown $^{a}$ & $1.82(0.23-14.66)$ & $1.53(0.19-12.53)$ \\
\hline \multicolumn{3}{|l|}{ Tumor stage } \\
\hline I-III & Ref & Ref \\
\hline IV & $2.14(1.08-4.24)$ & $1.94(0.94-3.98)$ \\
\hline Unknown $^{\mathrm{b}}$ & $4.10(1.08-15.53)$ & $2.64(0.51-13.73)$ \\
\hline \multicolumn{3}{|l|}{ Smoking } \\
\hline Never & Ref & Ref \\
\hline Current & $2.48(1.08-5.69)$ & $2.78(1.13-6.83)$ \\
\hline Previous & $1.82(0.81-4.11)$ & $1.90(0.78-4.59)$ \\
\hline Unknown $^{c}$ & $3.29(0.83-13.09)$ & $4.53(0.85-24.29)$ \\
\hline
\end{tabular}

The final model was adjusted for adjuvant therapy adherence, final stage according to the 7th edition of the AJCC Cancer Staging Manual, and smoking status. Excluding patients with "unknown "or "N/A" values for the covariates in the model did not result in significant changes $(<10 \%)$ in HRs, as shown in supplemental eTable 4.

Abbreviations: HR, hazard ratio; N/A, not available; S-PORT, time from surgery to postoperative radiotherapy; TTI, time to treatment initiation. ${ }^{a}$ Data were unavailable for 1 patient for all TTI and 1 patient for TTI $\leq 60 \mathrm{~d}$. ${ }^{\text {b}}$ Data were unavailable for 18 patients for all TTI and 17 patients for TTI $\leq 60 \mathrm{~d}$. 'Data were unavailable for 6 patients for all TTI and 4 patients for TTI $\leq 60 \mathrm{~d}$.

days versus 0 to 7 days (OR, 3.64; 95\% CI, 0.85-15.52), age $\geq 70$ versus $<50$ years (OR, 2.81; 95\% CI, 0.97-8.02), and $\mathrm{BMI}>30 \mathrm{~kg} / \mathrm{m}^{2}$ versus 18.5 to $30 \mathrm{~kg} / \mathrm{m}^{2}$ (OR, 2.28 ; 95\% CI, 0.98-5.29).

To identify individualized reasons for delayed S-PORT, medical charts of all patients with delayed S-PORT $(n=86)$ were reviewed (Table 3). The median S-PORT time among these patients was 65.5 days (range, 51-369 days). The

\begin{tabular}{|c|c|}
\hline \multicolumn{2}{|c|}{$\begin{array}{l}\text { Table 2. Multivariate Logistic Regression Model } \\
\text { of Factors Potentially Predictive of } \\
\text { Delayed S-PORT Based on Optimal } \\
\text { Threshold of } 50 \text { Days }\end{array}$} \\
\hline & OR $(95 \% \mathrm{Cl})$ \\
\hline Postoperative LoS: $8-30$ vs $0-7 \mathrm{~d}$ & $2.79(1.36-5.74)$ \\
\hline Postoperative LoS: $>30$ vs $0-7 d$ & $3.64(0.85-15.52)$ \\
\hline Age: $\geq 70$ vs $<50$ y & $2.81(0.97-8.02)$ \\
\hline BMI: $>30$ vs $18.5-30 \mathrm{~kg} / \mathrm{m}^{2}$ & $2.28(0.98-5.29)$ \\
\hline BMI: $<18.5$ vs $18.5-30 \mathrm{~kg} / \mathrm{m}^{2}$ & $3.98(1.11-14.21)$ \\
\hline
\end{tabular}

Only statistically significant predictors are shown. The full regression model can be found in supplemental eTable 3 . The final model was adjusted for postoperative LoS, age, and BMI.

Abbreviations: BMI, body mass index; LoS, length of stay; OR, odds ratio; $\mathrm{S}$-PORT, time from surgery to postoperative radiotherapy.

\begin{tabular}{|lc|}
\hline $\begin{array}{l}\text { Table 3. Reasons for Treatment Delay in Delayed } \\
\text { S-PORT Cohort }(\mathbf{n = 8 6 )}\end{array}$ & $\mathbf{n}(\%)$ \\
\hline Reason & $5(5.81)$ \\
\hline Additional reconstruction needed & $1(1.16)$ \\
\hline Changed treatment plan & $19(22.09)$ \\
\hline Complications related to surgery & $6(6.98)$ \\
\hline Nonadherence/Missed appointments & $2(2.33)$ \\
\hline Persistent disease requiring reresection & $16(18.60)$ \\
\hline Unrelated medical comorbidities & $37(43.02)$ \\
\hline Unknown
\end{tabular}

Abbreviation: S-PORT, time from surgery to postoperative radiotherapy.

most common reason was surgical complications $(\mathrm{n}=19$; $22.09 \%)$, including fistula $(\mathrm{n}=3)$, wound complications $(\mathrm{n}=7)$, and deconditioning $(\mathrm{n}=2)$. Another reason for delay was medical reasons related to patient comorbidities and hospital-acquired infections ( $\mathrm{n}=16 ; 18.60 \%)$, including pneumonia, nephrolithiasis, stroke, hemoperitoneum, lung mass surgery, and arrhythmias. Treatment-associated reasons for delay included nonadherence to or missed appointments $(\mathrm{n}=6 ; 6.98 \%)$, additional reconstruction $(n=5 ; 5.81 \%)$, persistent disease requiring reresection $(\mathrm{n}=2 ; 2.33 \%)$, and changed treatment plan $(\mathrm{n}=1 ; 1.16 \%)$.

\section{Discussion}

We investigated the impact of and reasons for nonadherence to NCCN Guidelines in S-PORT initiation for patients with HNSCC treated at an urban academic institution. When controlling for other influential factors, S-PORT $>50$ days corresponded to increased risk of recurrence and poorer OS. Regression analyses identified several risk factors for delayed S-PORT, including prolonged postoperative $\operatorname{LoS}$ ( $\geq 8$ days), being underweight $\left(\right.$ BMI $\left.<18.5 \mathrm{~kg} / \mathrm{m}^{2}\right)$ or obese (BMI $>30 \mathrm{~kg} / \mathrm{m}^{2}$ ), and advanced age ( $\geq 70$ years). Individualized reasons for S-PORT delay, including those related and unrelated to treatment, were also identified through chart review.

Although we previously established a negative impact of delayed surgical TTI on survival for patients with HNSCC independent of type of primary treatment, ${ }^{18}$ we found no independent association between TTI and survival within this cohort of patients with HSNCC receiving surgery with adjuvant RT. This result was consistent with a recent institutional study that found delayed treatment initiation did not impact survival in patients with HNSCC undergoing RT. ${ }^{19}$ The impact of S-PORT on survival was not confounded by TTI, and no significant association between delayed TTI and delayed S-PORT was identified, suggesting that the 2 delay intervals were independent. However, delayed TTI was found to be associated with greater recurrence. 
Most studies assessing delayed S-PORT in the United States have been based on national cancer registries. Three of 4 NCDB studies demonstrated that S-PORT delay beyond the NCCN-recommended 6 weeks correlated with worse survival. ${ }^{3,5,8,10}$ Another study used restricted cubic splines to demonstrate that S-PORT $>40$ days significantly impacted mortality, with each delay beyond this increasing mortality until 70 days postoperatively. ${ }^{7}$ Although national cancer registries provide large sample sizes for statistical power, they lack recurrence data and contain a heterogeneous population that may not correspond with institutional experiences. In addition, factors in delay cannot be easily evaluated through registry data. To facilitate future interventions, we therefore sought to validate the findings from national cancer registries in our population and to identify reasons for delay.

Two-thirds $(69.6 \% ; n=128)$ of our patients were considered to have received delayed S-PORT based on the NCCN recommendation of initiating PORT $\leq 6$ weeks after surgery. ${ }^{4}$ This was greater than the $55.3 \%$ of patients with S-PORT $>6$ weeks reported from NCDB data ${ }^{7}$ and may reflect the vulnerability of our population. Based on our recursive partitioning determined threshold of 50 days, $46.7 \%(n=86)$ of our patients experienced treatment delay, which was a slightly more lenient categorization of "delay" than the recommended NCCN definition.

Some studies have found delayed RT to have deleterious effects at different time points based on HNSCC stage. Fortin et $\mathrm{al}^{20}$ demonstrated that delayed RT for $>30$ days was associated with poorer outcomes in the T2N0 subgroup and that a delay $>40$ days was associated with increased risk of local failure in their institutional cohort. Although nonadherence to NCCN Guidelines contributes to poorer survival, the exact timing of S-PORT may differ institutionally. Contrary to this study by Fortin et al, our analysis found that the association between S-PORT and OS was most relevant for patients with advanced-stage disease (stage IV). Our subgroup analysis also showed that the association with S-PORT delay was most significant among those receiving RT only, without concurrent chemotherapy or cetuximab. Some studies have shown mitigation of adverse effects of delay with chemotherapy, although no consensus exists. ${ }^{17}$ Thus, further inquiry may elucidate the role of chemotherapy in PORT delay.

Studies that did not find associations between S-PORT and OS have been based on small, single-institution cohorts; used arbitrary intervals instead of the NCCN recommendation of $<6$ weeks; and/or focused only on specific HNSCC subsites. Tumati et $\mathrm{al}^{14}$ found delay in TTI, but not S-PORT, to be associated with lower survival in a single-institution report, using an S-PORT threshold determined by the 75th percentile among their cohort (67 days). Studies of RT delay for patients with oral cavity cancer failed to find an association between S-PORT delay and survival, ${ }^{15,16}$ in line with our study, which also found S-PORT delay not to be significantly associated with survival among patients with oral cavity cancer (HR, 1.22; 95\% CI, 0.58-2.59). Other studies looking at specific tumor subsites found associations between delayed S-PORT and survival to be significant for laryngeal cancer ${ }^{6}$ and sinonasal cancer. ${ }^{9}$ We also found that the impact of delayed S-PORT on survival among patients with HPV/p16-positive oropharyngeal cancer was not significant, which is consistent with most prior studies. ${ }^{21-23}$ However, in an NCDB study of oropharyngeal cancer, Goel et $\mathrm{al}^{24}$ found that delayed SPORT based on a 40-day threshold was associated with survival, regardless of p16 status.

Most studies using national cancer databases do not study the impact of treatment delay on recurrence. Although we were able to demonstrate that delayed S-PORT $>50$ days and TTI $>60$ days were both associated with recurrence in multivariable analyses, only delayed TTI remained significant during sensitivity analysis excluding patients with unknown variables. This may be a statistical artifact due to small sample size and requires further investigation with larger institutional cohorts. Another recent institutional cohort study showed a significant association between delayed S-PORT $>6$ weeks and recurrence-free survival, but not OS, in patients with oral cancer. ${ }^{16}$ A meta-analysis of 20 institutional studies conducted before 2005 showed that local control worsened with increased RT waiting time in multiple oncologic settings, including HNSCC. ${ }^{25}$

There has been less research on the predictors of treatment delay in HNSCC, especially among underserved and minority populations. We found that extended postoperative LoS, older age ( $\geq 70$ years), and underweight and obese patients were more likely to have delayed S-PORT. Extended LoS intuitively would delay the initiation of adjuvant therapy. Patients with underweight BMI may be sarcopenic, which leads to increased postoperative complications. ${ }^{26}$ Being underweight at diagnosis has been shown as an independent, adverse prognostic factor in HNSCC, whereas overweight BMI has conferred improved outcomes. ${ }^{27}$ Underweight BMI was found to be a predictor of delayed TTI at our institution, suggesting that BMI may play a role in multiple intervals of treatment delays. ${ }^{18}$ Underweight BMI may predispose patients to deconditioning, which was a complication associated with delayed S-PORT. Overweight patients have also shown significantly better OS than normal-weight patients, independent of comorbidities, at our institution. ${ }^{28}$ In contrast to a previous analysis that found diagnosis at a different institution to be associated with delayed TTI, ${ }^{18}$ we found no significant association between the location of diagnosis and delayed S-PORT. Finally, a recent institutional cohort study showed that African American patients had an absolute increase in the rate of PORT relative to White patients. ${ }^{29}$ We found no significant association between 
race and PORT delay, which may be secondary to our institution's primarily serving minorities (43\% cohort) and to our limited sample size.

Exploring individualized reasons for delayed S-PORT in our cohort may elucidate areas for intervention. The most common reason was complications related to surgery, whereas other recurrent reasons included unrelated medical reasons and nonadherence. Better understanding of these reasons and implementing solutions will require a quality improvement approach that involves establishing treatment timelines, interviews, and education. An intervention targeting delayed dental evaluation, radiation oncology consults, and patient engagement has been used to successfully reduce RT initiation delay. ${ }^{30}$ Another study found that early extractions were significantly associated with decreased risk of delay. ${ }^{31}$ Finally, a recent study found that patients undergoing RT consultation before surgery were 9 times more likely to receive timely PORT, and $<10$ days between surgery and RT referral made timely PORT 10 times more likely. ${ }^{29}$

Because this was a retrospective study, accuracy was limited by patient records in which miscoding errors may have been present. The rareness of this tumor limited the study sample size and power. Furthermore, missing data in patient records were more likely for earlier cases, when electronic health records were unavailable. We opted not to impute missing values, because our data did not satisfy the missing-at-random assumption. Although the single-institution nature of this study may provide insight into the role of treatment delay in the setting of an underserved population at an urban medical center, it may be less generalizable to other populations. Because of missing time-to-recurrence information, we were unable to analyze recurrence using Cox regression. We were also unable to capture pathologic results, which increases the potential for confounding bias. However, the use of postoperative chemoradiation in the management of patients in this cohort partially serves as a surrogate marker for adverse pathologic features. Surgery type was also not available, and we controlled for $\mathrm{T}$ staging.
Although $\mathrm{T}$ staging does not always correlate with exact size, minimally invasive surgeries are rarely performed for those tumors that are T3. Thus, T staging was deemed a reasonable surrogate for this variable.

\section{Conclusions}

Our study findings showed that delayed PORT beyond 50 days after surgery was associated with decreased OS and greater recurrence. The association between delayed S-PORT and OS was most significant in patients with stage IV disease, with laryngeal cancer, or receiving radiotherapy only, without concurrent chemotherapy or cetuximab. We also found that the impact of S-PORT on OS in HPV/p16-positive oropharyngeal cancer was not significant. Postoperative LoS, age $>70$ years, and underweight and obese BMIs were associated with delayed S-PORT. Identification of predictive factors and reasons for treatment delay will help target at-risk patients and facilitate interventions in underserved populations.

Submitted July 30, 2020; final revision received January 12, 2021; accepted for publication January 13, 2021.

Published online September 22, 2021.

Author contributions: Study concept and design: Ponduri, Liao, Schlecht Mehta. Data acquisition: Ponduri, Liao, Schlecht, Kabarriti, Garg. Data analysis: Ponduri, Liao, Schlecht, Kabarriti, Garg, Mehta. Data interpretation: Schlecht, Kabarriti, Garg, Mehta. Statistical analysis: Ponduri, Liao, Schlecht, Rosenblatt. Quality control of data and algorithms: Schlecht, Rosenblatt, Mehta. Writing - original draft: Ponduri, Liao, Mehta Writing - review and editing: Ponduri, Liao, Prystowsky, Kabarriti, Garg, Ow, Schiff, Smith, Mehta.

Disclosures: The authors have disclosed that they have not received any financial consideration from any person or organization to support the preparation, analysis, results, or discussion of this article.

Funding: Research reported in this publication was supported by the $\mathrm{NCl}$ of the NIH under award numbers CA013330 and CA016056.

Disclaimer: The content is solely the responsibility of the authors and does not necessarily represent the official views of the $\mathrm{NIH}$.

Correspondence: Vikas Mehta, MD, MPH, Department of OtorhinolaryngologyHead and Neck Surgery, Montefiore Medical Center, 3400 Bainbridge Avenue, 3rd Floor, MAP Building, Bronx, NY 10467. Email: dr.vikasmehta@gmail.com

\section{References}

1. Jensen AR, Nellemann HM, Overgaard J. Tumor progression in waiting time for radiotherapy in head and neck cancer. Radiother Oncol 2007;84: 5-10.

2. Mackillop WJ, Bates JH, O'Sullivan B, et al. The effect of delay in treatment on local control by radiotherapy. Int J Radiat Oncol Biol Phys 1996;34:243250.

3. Graboyes EM, Kompelli AR, Neskey DM, et al. Association of treatment delays with survival for patients with head and neck cancer: a systematic review. JAMA Otolaryngol Head Neck Surg 2019;145:166-177.

4. Pfister DG, Spencer S, Adelstein D, et al. NCCN Clinical Practice Guidelines in Oncology: Head and Neck Cancers. Version 3.2021. Accessed April 30, 2021. To view the most recent version, visit NCCN.org
5. Tam M, Wu SP, Gerber NK, et al. The impact of adjuvant chemoradiotherapy timing on survival of head and neck cancers. Laryngoscope 2018; 128:2326-2332.

6. Morse E, Fujiwara RJT, Judson B, et al. Treatment delays in laryngeal squamous cell carcinoma: a National Cancer Database analysis. Laryngoscope 2018;128:2751-2758.

7. Ho AS, Kim S, Tighiouart M, et al. Quantitative survival impact of composite treatment delays in head and neck cancer. Cancer 2018;124:3154-3162.

8. Graboyes EM, Garrett-Mayer E, Ellis MA, et al. Effect of time to initiation of postoperative radiation therapy on survival in surgically managed head and neck cancer. Cancer 2017;123:4841-4850.

9. Goel AN, Lee JT, Wang MB, et al. Treatment delays in surgically managed sinonasal cancer and association with survival. Laryngoscope 2020;130:2-11. 
10. Cramer JD, Speedy SE, Ferris RL, et al. National evaluation of multidisciplinary quality metrics for head and neck cancer. Cancer 2017;123:43724381.

11. Lewis CM, Hessel AC, Roberts DB, et al. Prereferral head and neck cancer treatment: compliance with National Comprehensive Cancer Network treatment guidelines. Arch Otolaryngol Head Neck Surg 2010;136:12051211.

12. Graboyes EM, Garrett-Mayer E, Sharma AK, et al. Adherence to National Comprehensive Cancer Network guidelines for time to initiation of postoperative radiation therapy for patients with head and neck cancer. Cancer 2017;123:2651-2660.

13. United States Census Bureau. QuickFacts: Bronx County (Bronx Borough), New York. 2017. Accessed April 10, 2019. Available at: https://www. census.gov/quickfacts/fact/table/bronxcountybronxboroughnewyork/ SEX255217

14. Tumati $V$, Hoang $L$, Sumer BD, et al. Association between treatment delays and oncologic outcome in patients treated with surgery and radiotherapy for head and neck cancer. Head Neck 2019;41:315-321.

15. Fujiwara RJ, Judson BL, Yarbrough WG, et al. Treatment delays in oral cavity squamous cell carcinoma and association with survival. Head Neck 2017;39:639-646.

16. Chen MM, Harris JP, Orosco RK, et al. Association of time between surgery and adjuvant therapy with survival in oral cavity cancer. Otolaryngol Head Neck Surg 2018;158:1051-1056.

17. Marshak G, Popovtzer A. Is there any significant reduction of patients' outcome following delay in commencing postoperative radiotherapy? Curr Opin Otolaryngol Head Neck Surg 2006;14:82-84.

18. Liao DZ, Schlecht NF, Rosenblatt G, et al. Association of delayed time to treatment initiation with overall survival and recurrence among patients with head and neck squamous cell carcinoma in an underserved urban population. JAMA Otolaryngol Head Neck Surg 2019; 145:1001-1009.

19. DeGraaff LH, Platek AJ, lovoli AJ, et al. The effect of time between diagnosis and initiation of treatment on outcomes in patients with head and neck squamous cell carcinoma. Oral Oncol 2019;96:148-152.
20. Fortin A, Bairati I, Albert M, et al. Effect of treatment delay on outcome of patients with early-stage head-and-neck carcinoma receiving radical radiotherapy. Int J Radiat Oncol Biol Phys 2002;52:929-936.

21. Bastit $L$, Blot $E$, Debourdeau $P$, et al. Influence of the delay of adjuvant postoperative radiation therapy on relapse and survival in oropharyngeal and hypopharyngeal cancers. Int J Radiat Oncol Biol Phys 2001;49:139-146.

22. Sievert M, Goncalves M, Mueller SK, et al. Impact of delayed adjuvant therapy after surgery in $\mathrm{p} 16$ positive oropharyngeal cancer: a retrospective analysis. Eur Rev Med Pharmacol Sci 2020;24:1211-1218.

23. Townsend M, DeWees T, Gross J, et al. Timing of postoperative radiotherapy in surgically treated HPV-positive oropharyngeal squamous cell carcinoma. Otolaryngol Head Neck Surg 2019;161:297-306.

24. Goel AN, Frangos M, Raghavan G, et al. Survival impact of treatment delays in surgically managed oropharyngeal cancer and the role of human papillomavirus status. Head Neck 2019;41:1756-1769.

25. Chen Z, King W, Pearcey R, et al. The relationship between waiting time for radiotherapy and clinical outcomes: a systematic review of the literature. Radiother Oncol 2008;87:3-16.

26. Achim V, Bash J, Mowery A, et al. Prognostic indication of sarcopenia for wound complication after total laryngectomy. JAMA Otolaryngol Head Neck Surg 2017;143:1159-1165.

27. Gama RR, Song Y, Zhang Q, et al. Body mass index and prognosis in patients with head and neck cancer. Head Neck 2017;39:1226-1233.

28. Fattouh M, Chang GY, Ow TJ, et al. Association between pretreatment obesity, sarcopenia, and survival in patients with head and neck cancer. Head Neck 2019;41:707-714.

29. Janz TA, Kim J, Hill EG, et al. Association of care processes with timely, equitable postoperative radiotherapy in patients with surgically treated head and neck squamous cell carcinoma. JAMA Otolaryngol Head Neck Surg 2018;144:1105-1114.

30. Divi V, Chen MM, Hara W, et al. Reducing the time from surgery to adjuvant radiation therapy: an institutional quality improvement project. Otolaryngol Head Neck Surg 2018;159:158-165.

31. Strohl MP, Chen JP, Ha PK, et al. Can early dental extractions reduce delays in postoperative radiation for patients with advanced oral cavity carcinoma? J Oral Maxillofac Surg 2019;77:2215-2220. 
Supplemental online content for:

\section{Impact of Nonadherence to}

NCCN Adjuvant Radiotherapy Initiation Guidelines in Head and Neck Squamous Cell Carcinoma in an Underserved Urban Population

Anusha Ponduri, BA; David Z. Liao, MD; Nicolas F. Schlecht, PhD; Gregory Rosenblatt, PhD;

Michael B. Prystowsky, MD, PhD; Rafi Kabarriti, MD; Madhur Garg, MD, MBA; Thomas J. Ow, MD, MS;

Bradley A. Schiff, MD; Richard V. Smith, MD; and Vikas Mehta, MD, MPH

J Natl Compr Canc Netw, doi: 10.6004/jnccn.2021.7007

eFigure 1: Diagram of Cohort Creation With Exclusion Criteria

eTable 1: Patient Characteristics Based on S-PORT Threshold of 50 Days

eTable 2: Multivariate Cox Regression Analysis for Overall Survival

eTable 3: Hazard Ratios for S-PORT $>50$ Versus $\leq 50$ Days in Subgroup Analyses

eTable 4: Multivariate Logistic Regression Models for Recurrence

eTable 5: Full Multivariate Logistic Regression of Factors Predicting Delayed TTI Based on Optimal

Threshold of 60 Days 


\section{Ponduri et al}

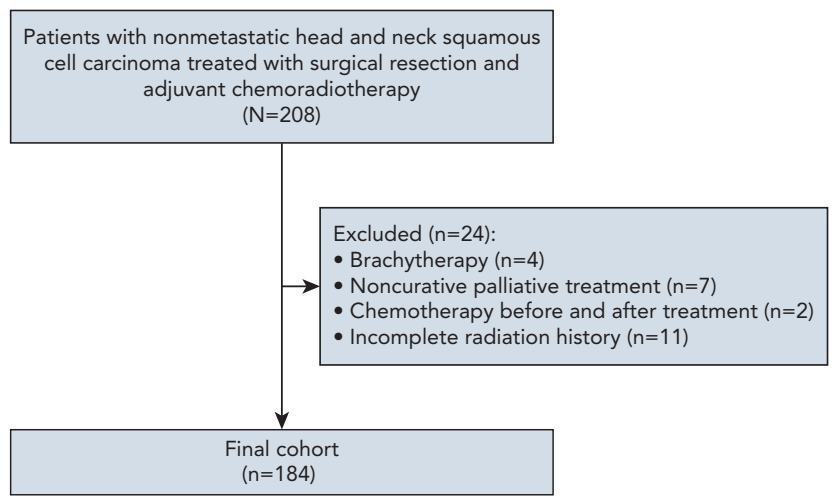

eFigure 1. Diagram of cohort creation with exclusion criteria. 


\section{eTable 1. Patient Characteristics Based on S-PORT Threshold of 50 Days}

\begin{tabular}{|lr}
\hline Characteristic & Tot \\
\hline Total, $\mathrm{n}$ & 18 \\
\hline $\begin{array}{l}\text { Sex } \\
\text { Male }\end{array}$ & 13 \\
\hline Female & 51 \\
\hline Age & 24 \\
\hline$<50 y$ & 49 \\
\hline $50-59 y$ & 60 \\
\hline $60-69 y$ & 51 \\
\hline$\geq 70 y$ &
\end{tabular}

\begin{tabular}{|c|c|}
\hline otal & $\begin{array}{c}\text { Patients With } \\
\text { S-PORT } \leq 50 \mathrm{~d} \\
n(\%)\end{array}$ \\
\hline 184 & 98 \\
\hline
\end{tabular}

Patients With
S-PORT >50 o
n (\%)

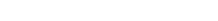

$\begin{array}{ll}72(73.5) & 61(70.9)\end{array}$

BMI

$\begin{array}{lll}24 & 14(14.3) & 10(11.6) \\ 49 & 31(31.6) & 18(20.9) \\ 60 & 23(23.5) & 37(43.0) \\ 51 & 30(30.6) & 21(24.4)\end{array}$

$>30 \mathrm{~kg} / \mathrm{m}^{2}$

$18.5-30 \mathrm{~kg} / \mathrm{m}^{2}$

$34 \quad 15(15.3)$

$19(22.1)$

$<18.5 \mathrm{~kg} / \mathrm{m}^{2}$

15

Unknown

13

70 (71.4)

$52(60.5)$

Race/Ethnicity

13

$4(4.1)$

11 (12.8)

9 (9.2)

$4(4.7)$

\begin{tabular}{llll}
\hline Hispanic & 49 & $24(24.5)$ & $25(29.1)$ \\
\hline African American & 44 & $18(18.4)$ & $26(30.2)$ \\
\hline Non-Hispanic White & 44 & $25(25.5)$ & $19(22.1)$ \\
\hline Unknown & 47 & $31(31.6)$ & $16(18.6)$
\end{tabular}

Language

142

$(78,6)$

1.34

\begin{tabular}{lr}
\hline English & 142 \\
\hline Non-English & 38 \\
\hline Unknown &
\end{tabular}

Insurance

38

77 (78.6)

65 (75.6)

$20(20.4)$

18 (20.9)

$4 \quad 1(1.0)$

3 (3.5)

\begin{tabular}{lccc}
\hline Medicaid & 54 & $29(29.6)$ & $25(29.1)$ \\
\hline Medicare & 64 & $33(33.7)$ & $31(36.0)$ \\
\hline Commercial & 35 & $21(21.4)$ & $14(16.3)$ \\
\hline Self-pay & 1 & $1(1.0)$ & $0(0.0)$ \\
\hline N/A & 3 & $1(1.0)$ & $2(2.3)$ \\
\hline Other & 27 & $13(13.3)$ & $14(16.3)$
\end{tabular}

Socioeconomic status ${ }^{\mathrm{a}}$

\begin{tabular}{ll}
\hline First quartile: $<-6.36$ & 44 \\
\hline Second quartile: -6.36 to -2.10 & 44 \\
\hline Third quartile: -2.11 to -0.76 & 43 \\
\hline Fourth quartile: $>-0.76$ & \\
\hline N/A &
\end{tabular}

$\begin{array}{rrc}44 & 21(21.4) & 23(26.7) \\ 44 & 23(23.5) & 21(24.4) \\ 44 & 20(20.4) & 24(27.9) \\ 43 & 28(28.6) & 15(17.5) \\ 9 & 6(96.1) & 3(3.5)\end{array}$

Diagnosis at different institute

\begin{tabular}{lrrr}
\hline No & 77 & $36(36.7)$ & $41(47.7)$ \\
\hline Yes & 107 & $62(63.3)$ & $45(52.3)$
\end{tabular}

$\mathrm{CCl}$ score

\begin{tabular}{lr}
\hline 0 & 156 \\
\hline 1 & 4 \\
\hline 2 & 24
\end{tabular}

$\begin{array}{rc}156 & 83(84.7) \\ 4 & 2(2.0) \\ 24 & 13(13.3)\end{array}$

$73(84.9)$
$2(2.3)$
$11(12.8)$

0.15 


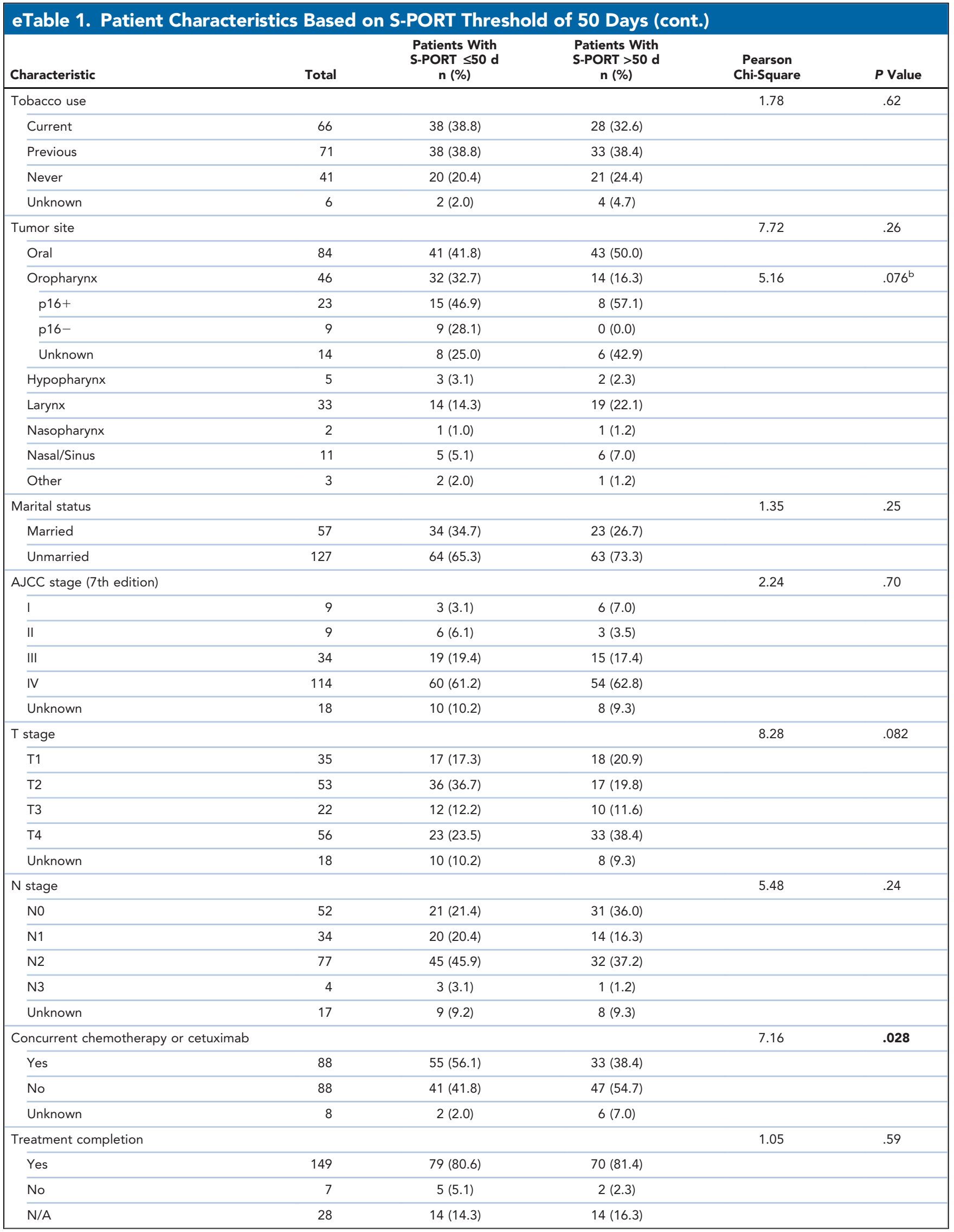




\begin{tabular}{|c|c|c|c|c|c|}
\hline Characteristic & Total & $\begin{array}{c}\text { Patients With } \\
\text { S-PORT } \leq 50 \mathrm{~d} \\
n(\%)\end{array}$ & $\begin{array}{c}\text { Patients With } \\
\text { S-PORT > 50 d } \\
n(\%)\end{array}$ & $\begin{array}{l}\text { Pearson } \\
\text { Chi-Square }\end{array}$ & $P$ Value \\
\hline Adherent to recommended treatment & & & & 0.52 & .47 \\
\hline Yes & 150 & $78(79.6)$ & 72 (83.7) & & \\
\hline No & 34 & $20(20.4)$ & $14(16.3)$ & & \\
\hline 30-d readmission & & & & 7.12 & .028 \\
\hline Yes & 34 & $12(12.2)$ & $22(25.6)$ & & \\
\hline No & 120 & $72(73.5)$ & $48(55.8)$ & & \\
\hline Unknown & 30 & $14(14.3)$ & $16(18.6)$ & & \\
\hline Postoperative LoS & & & & 12.24 & .007 \\
\hline $0-7 d$ & 76 & $52(53.1)$ & $24(27.9)$ & & \\
\hline $8-30 d$ & 68 & $28(28.6)$ & $40(46.5)$ & & \\
\hline$>30 \mathrm{~d}$ & 10 & $4(4.1)$ & $6(7.0)$ & & \\
\hline Unknown & 30 & $14(14.3)$ & $16(18.6)$ & & \\
\hline Time to treatment initiation & & & & 2.75 & .097 \\
\hline$>60 \mathrm{~d}$ & 24 & $9(9.2)$ & $15(17.4)$ & & \\
\hline$\leq 60 \mathrm{~d}$ & 160 & $89(90.8)$ & $71(82.6)$ & & \\
\hline Date of diagnosis & & & & 0.04 & .981 \\
\hline $1 / 1 / 2005-12 / 31 / 2009$ & 70 & 37 (52.9) & $33(47.2)$ & & \\
\hline $1 / 1 / 2010-12 / 31 / 2014$ & 83 & $44(53.0)$ & $39(47.0)$ & & \\
\hline 1/1/2015-present & 31 & $17(54.8)$ & $14(45.2)$ & & \\
\hline
\end{tabular}

Bold indicates statistically significant $P$ value.

Abbreviations: BMI, body mass index; CCl, Charlson-Deyo comorbidity index; LoS, length of stay; N/A, not available; S-PORT, time from surgery to postoperative radiotherapy.

${ }^{\text {a } Q u a r t i l e s ~ w e r e ~ d e t e r m i n e d ~ b y ~ m e t h o d ~ o u t l i n e d ~ b y ~ D i e z ~ R o u x ~ e t ~ a l . ~}{ }^{1}$ Quartiles were determined by patient's address, geocoded to a census block, with a neighborhood SES score determined. Each quartile score reflects the number of standard deviations from the mean SES score of NY census blocks.

${ }^{\mathrm{b}} \mathrm{P}$ value based on chi-square test of $\mathrm{p} 16$ status among patients with oropharyngeal cancer.

\section{Reference}

1. Diez Roux AV, Merkin SS, Arnett D, et al. Neighborhood of residence and incidence of coronary heart disease. N Engl J Med 2001;345:99-106. 


\section{eTable 2. Multivariate Cox Regression Analysis} for Overall Survival

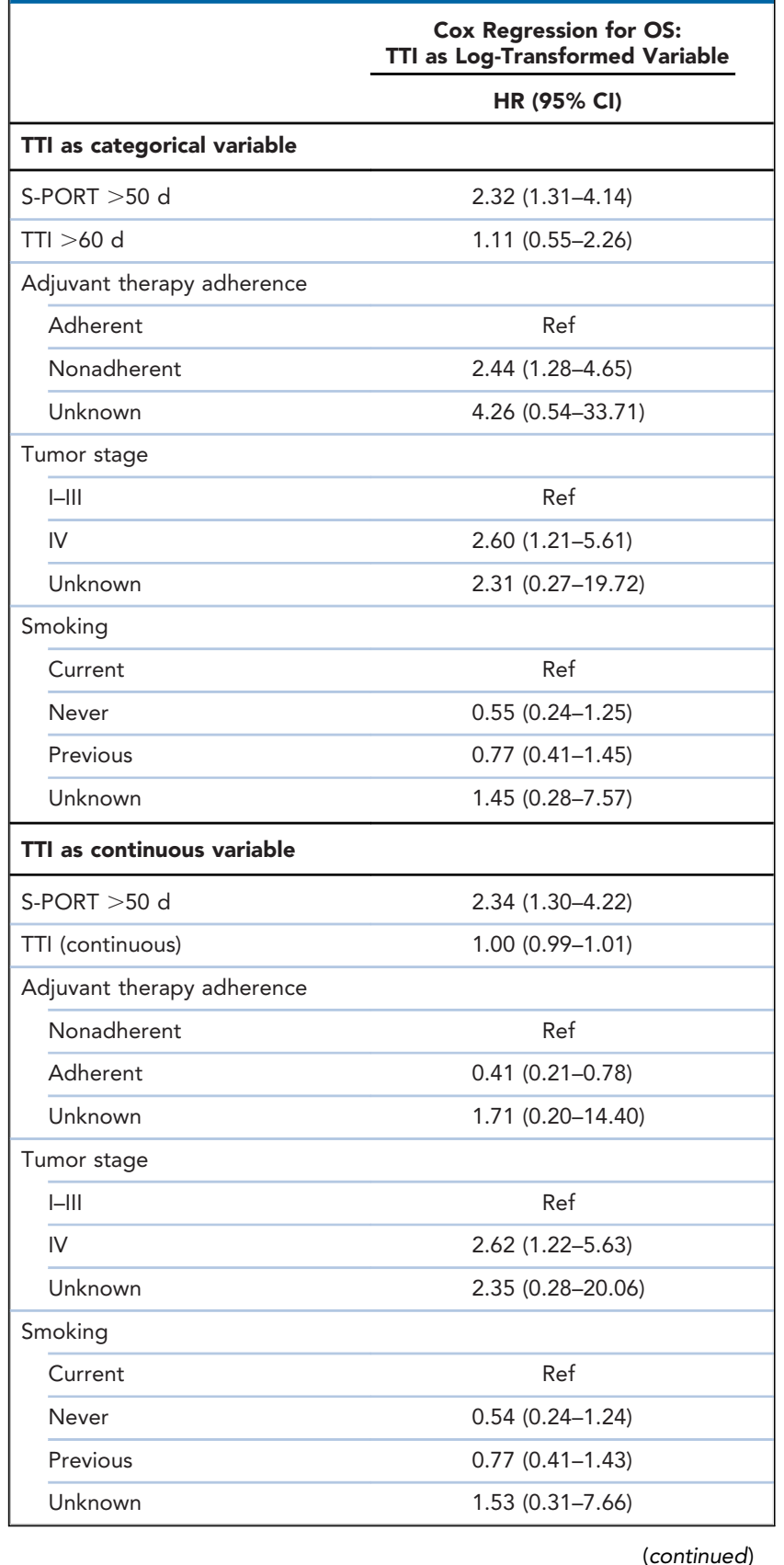

\section{eTable 2. Multivariate Cox Regression Analysis} for Overall Survival (cont.)

Cox Regression for OS: TTI as Log-Transformed Variable $\operatorname{HR}(95 \% \mathrm{Cl})$

\begin{tabular}{|lc|}
\hline TTI as log-transformed variable & \\
\hline S-PORT $>50 \mathrm{~d}$ & $2.28(1.27-4.11)$ \\
\hline Log (TTI) & $1.09(0.73-1.63)$ \\
\hline $\begin{array}{l}\text { Adjuvant therapy adherence } \\
\text { Nonadherent }\end{array}$ & $0.41(0.22-0.79)$ \\
\hline Adherent & $1.84(0.22-15.50)$ \\
\hline Unknown & Ref \\
\hline Tumor stage & $2.62(1.22-5.64)$ \\
\hline I-III & $2.33(0.27-19.82)$ \\
\hline IV & Ref \\
\hline Unknown & $0.55(0.24-1.25)$ \\
\hline Smoking & $0.77(0.41-1.44)$ \\
\hline Current & $1.55(0.31-7.73)$ \\
\hline Never & \\
\hline Previous & Unknown \\
\hline
\end{tabular}

Models were generated with TTI as a categorical variable ( $>60$ vs $\leq 60$ days) continuous variable, and log-transformed variable.

Abbreviations: HR, hazard ratio; OS, overall survival; S-PORT, time

from surgery to postoperative radiotherapy; TTI, time to treatment initiation. 


\section{eTable 3. Hazard Ratios for S-PORT $>50$ Versus} $\leq \mathbf{5 0}$ Days in Subgroup Analyses

\begin{tabular}{|lc|}
\hline \multicolumn{1}{|c|}{ HR $(95 \% \mathrm{Cl})$} \\
\hline \begin{tabular}{l} 
Tumor site \\
\hline Larynx
\end{tabular} & $4.78(0.96-23.95)$ \\
\hline Oropharynx & $3.44(0.67-17.58)$ \\
\hline Other ${ }^{\mathrm{a}}$ & $1.22(0.58-2.59)$ \\
\hline p16 status & $2.36(0.36-15.38)$ \\
\hline p16+ OPC & $2.44(0.21-28.20)$ \\
\hline p16- or unknown OPC & $10.81(0.96-121.65)$ \\
\hline P16- or unknown (any site) & $2.31(1.32-4.05)$ \\
\hline Yes & $1.32(0.62-2.79)$ \\
\hline No & $5.80(2.06-16.32)$ \\
\hline Final tumor stage & \\
\hline I-III & $2.41(0.67-8.65)$ \\
\hline IV & $2.21(1.18-4.12)$ \\
\hline
\end{tabular}

HRs are adjusted for the remainder covariates in the multivariate Cox regression in Table 3.

Abbreviations: HR, hazard ratio; OPC, oropharyngeal cancer; S-PORT, time from surgery to postoperative radiotherapy

aNasopharynx, nasal, hypopharynx, other. 


\section{eTable 4. Multivariate Logistic Regression Models for Recurrence}

\begin{tabular}{|c|c|c|}
\hline & $\begin{array}{l}\text { Recurrence } \\
\text { OR }(95 \% \mathrm{Cl})\end{array}$ & $\begin{array}{c}\text { Recurrence Excluding Unknowns } \\
\text { OR }(95 \% \mathrm{CI})\end{array}$ \\
\hline S-PORT >50 d & $3.51(1.31-9.39)$ & $1.66(0.51-5.40)$ \\
\hline $\mathrm{TTI}>60 \mathrm{~d}$ & $3.57(1.05-12.19)$ & $3.51(1.25-19.42)$ \\
\hline \multicolumn{3}{|l|}{ BMI category } \\
\hline $18.5-30 \mathrm{~kg} / \mathrm{m}^{2}$ & Ref & Ref \\
\hline$<18.5 \mathrm{~kg} / \mathrm{m}^{2}$ & $0.73(0.09-5.63)$ & $0.94(0.12-7.62)$ \\
\hline$>30 \mathrm{~kg} / \mathrm{m}^{2}$ & $4.1(1.38-12.16)$ & $7.91(2.03-30.87)$ \\
\hline Unknown $^{a}$ & $4.33(0.674-27.81)$ & \\
\hline Postoperative LoS & $1.94(0.94-3.98)$ & \\
\hline $0-7 d$ & Ref & Ref \\
\hline $8-30 d$ & $2.64(0.51-13.73)$ & $7.08(1.70-29.55)$ \\
\hline$>30 d$ & $1.26(0.10-16.11)$ & $5.34(0.32-89.30)$ \\
\hline Unknown $^{\mathrm{b}}$ & $4.38(0.87-22.10)$ & \\
\hline Adherent to treatment & $0.09(0.03-0.34)$ & $0.05(0.01-0.24)$ \\
\hline \multicolumn{3}{|l|}{ Tumor stage } \\
\hline I-III & Ref & Ref \\
\hline IV & $1.51(0.54-4.22)$ & $0.72(0.22-2.41)$ \\
\hline Unknown $^{c}$ & $1.08(0.19-6.09)$ & \\
\hline
\end{tabular}

Models were generated that included and excluded patients with unknown covariate values. The final model was adjusted for TTI > 60 days, BMI, postoperative LoS, treatment adherence, and AJCC final stage.

Abbreviations: BMI, body mass index; LoS, length of stay; OR, odds ratio; S-PORT, time from surgery to postoperative radiotherapy; TTI, time to treatment initiation.

a7 patients had unknown BMI.

b12 patients had unknown postoperative LoS.

${ }^{\mathrm{c}} 15$ patients had unknown stage. 


\section{eTable 5. Full Multivariate Logistic Regression \\ of Factors Predicting Delayed TTI \\ Based on Optimal Threshold of 60 Days}

\begin{tabular}{|lc|}
\hline BMl category & OR (95\% CI) \\
\hline $\begin{array}{l}18.5-30 \mathrm{~kg} / \mathrm{m}^{2} \\
<18.5 \mathrm{~kg} / \mathrm{m}^{2}\end{array}$ & Ref \\
\hline$>30 \mathrm{~kg} / \mathrm{m}^{2}$ & $3.98(1.11-14.21)$ \\
\hline $\mathrm{N} / \mathrm{A}$ & $2.28(0.98-5.29)$ \\
\hline Postoperative LoS & $0.57(0.16-2.12)$ \\
\hline $0-7 \mathrm{~d}$ & Ref \\
\hline $8-30 \mathrm{~d}$ & $2.79(1.36-5.74)$ \\
\hline$>30 \mathrm{~d}$ & $3.64(0.85-15.52)$ \\
\hline $\mathrm{N} / \mathrm{A}$ & $3.41(1.33-8.73)$ \\
\hline Age & \\
\hline$<50 \mathrm{y}$ & $1.03(0.36-2.96)$ \\
\hline $50-59 \mathrm{y}$ & $0.91(0.31-2.65)$ \\
\hline $60-69 \mathrm{y}$ & $2.81(0.99-8.02)$ \\
\hline$\geq 70 \mathrm{y}$ &
\end{tabular}

Abbreviations: BMI, body mass index; LoS, length of stay; N/A, not available; OR, odds ratio; TTI, time to treatment initiation. 